\title{
Christian Sorrel (dir.), Alexandre Glasberg 1902-1981. Prêtre, Résistant, Militant
}

Lyon, LARHRA - RESEA, coll. "Chrétiens et Sociétés, Documents et Mémoires ", 19, 2013, 164 p.

\section{Michael Löwy}

\section{(2) OpenEdition}

\section{Journals}

Édition électronique

URL : http://journals.openedition.org/assr/27464

DOI : $10.4000 /$ assr.27464

ISSN : $1777-5825$

Éditeur

Éditions de l'EHESS

Édition imprimée

Date de publication : 1 octobre 2015

Pagination : 374

ISBN : 978-2-7132-2515-4

ISSN : 0335-5985

Référence électronique

Michael Löwy, «Christian Sorrel (dir.), Alexandre Glasberg 1902-1981. Prêtre, Résistant, Militant », Archives de sciences sociales des religions [En ligne], 172 | octobre-décembre, mis en ligne le 21 juin 2016, consulté le 23 septembre 2020. URL : http://journals.openedition.org/assr/27464 ; DOI : https:// doi.org/10.4000/assr.27464

Ce document a été généré automatiquement le 23 septembre 2020.

(c) Archives de sciences sociales des religions 


\section{Christian Sorrel (dir.), Alexandre Glasberg 1902-1981. Prêtre, Résistant, Militant}

Lyon, LARHRA - RESEA, coll. « Chrétiens et Sociétés, Documents et Mémoires ", 19, 2013, 164 p.

Michael Löwy

\section{RÉFÉRENCE}

Christian Sorrel (dir.), Alexandre Glasberg 1902-1981. Prêtre, Résistant, Militant, Lyon, LARHRA - RESEA, coll. «Chrétiens et Sociétés, Documents et Mémoires », 19, 2013, $164 \mathrm{p}$. 
1 Il s'agit des Actes de la Journée d'étude du 24 mai 2012, organisée à l'Université de Lyon par l'équipe Religions, Sociétés Et Acculturation $\mathrm{du}$ Laboratoire de Recherche Historique Rhône-Alpes (UMR 5190), autour de la personne de l'abbé Glasberg, Juif converti au catholicisme, sauveur de centaines de Juifs pendant l'Occupation, résistant, protecteur des réfugiés et exilés politiques, militant tiersmondiste.

2 "Énigme ", " mystère ", "secret » sont des termes qui reviennent souvent lors des communications ici publiées, au sujet de l'itinéraire singulier et surprenant d'Alexandre Glasberg. Né à Jitomir en Volhynie (Ukraine, province de la Russie tsariste) dans une famille juive non croyante qui va immigrer dans les années

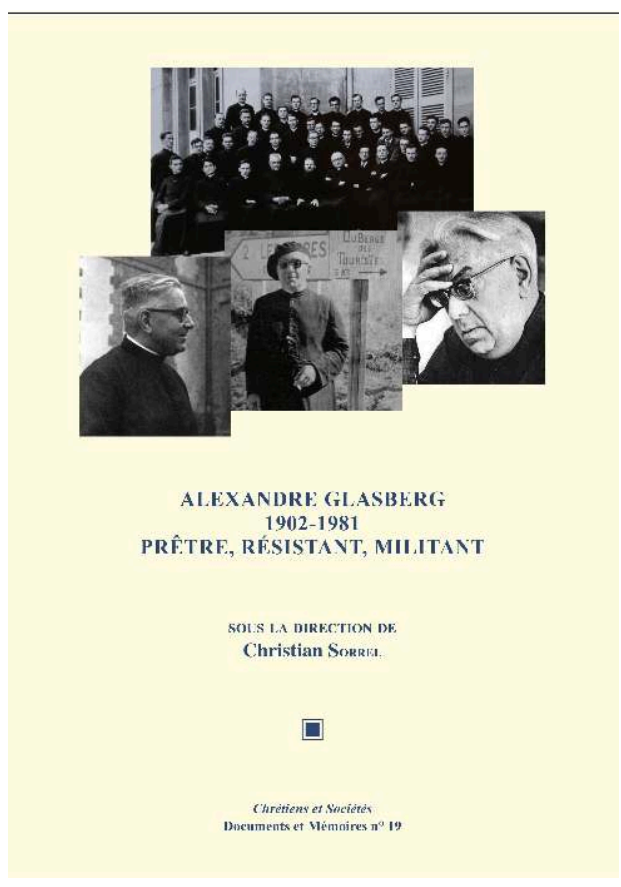
1920, le jeune Glasberg se convertit, à une date et lieu inconnus - le premier mystère au christianisme, d'abord dans sa version luthérienne, et après - quand ? Où ? - au catholicisme. Après un séjour en Pologne et en Yougoslavie, et des passages par Berlin et Vienne, il arrive à Paris en 1932. Aspirant au sacerdoce, il entre en 1934 chez les Pères Maristes, étudie au séminaire de Lyon, devient prêtre en 1938 et est détaché au diocèse de Lyon en 1940. L'abbé, qui n'a pas laissé de papiers ni écrit ses mémoires, a toujours gardé le silence sur les raisons de sa conversion et aucune des personnes l'ayant connu ou joui de son amitié n'a eu connaissance de ses motivations (enquêtes de Roger Millot et Christian Sorrel).

Dès 1940 commence une étape décisive de sa vie : les opérations de sauvetage des Juifs persécutés par Vichy et par les forces d'occupation (communication de Madeleine Comte). Tandis que Helbronner, le Président du Consistoire israélite, réfugié à Lyon, prie son ami d'études, le Cardinal Gerlier, de ne pas soulever la question des Juifs étrangers internés dans des camps pour «ne pas aggraver la situation des israélites français " (!), l'abbé Glasberg demande au Cardinal d'intervenir auprès de Vichy en faveur de ces réfugiés. Et surtout, il met sur place des réseaux d'aide - notamment l'Amitié Chrétienne, créée avec le Père Jésuite Chaillet, fondateur de Témoignage Chrétien - qui utilisent des méthodes peu orthodoxes (fabrication de faux papiers) pour cacher et protéger les Juifs persécutés par la Préfecture de Police. Grâce à son action, une centaine d'enfants juifs du camp de Vénissieux sont sauvés. Plusieurs autres centaines de réfugiés juifs seront sauvés par Alexandre Glasberg. Les activités de l'abbé sont dénoncées par la presse collaborationniste et en janvier 1943, la Gestapo de Barbie fait une descente à l'Amitié Chrétienne, dont les animateurs (le Père Chaillet et JeanMarie Soutou) seront, pour une brève période, arrêtés.

4 À partir de ce moment, l'abbé Glasberg entre en clandestinité : quittant Lyon, il trouve refuge au diocèse de Montauban, dont l'évêque, Mgr Théas, le nomme, sous le nom d'«abbé Corvin ", à la paroisse de la commune de L'Honor-de-Cos. Le nouvel abbé ne reste pas inactif : bientôt, sous le pseudonyme «Élie », il va participer à la résistance, 
fournissant des mitraillettes au maquis de Saint-Antonin, organisant des parachutages, etc. En juin 1944, "Élie " participe à la fondation du maquis de Saint-Amans et à la création du Comité départemental de Libération du Tarn-et-Garonne, où il siégera jusqu'à décembre de cette année (communication de Norbert Sabatié).

5 Le rôle de l'abbé Glasberg dans le sauvetage des Juifs pendant la guerre lui vaudra, à titre posthume, la médaille de Juste parmi les Nations (attribuée par Israël), en 2004, c'est-à-dire... 23 ans après sa mort. Le retard semble dû à sa double identité de prêtre chrétien et de Juif (comm. de Cindy Banse).

Dans l'après-guerre, il s'occupe de la Direction de Centres d'Accueil, du Centre d'orientation sociale des étrangers, et, plus tard, de France Terre d'Asile, qui apportent une aide efficace à des réfugiés et internés juifs, plus tard à des exilés politiques du Tiers-Monde (comm. Axelle Bordiez). Partisan d'un sionisme socialiste et laïc, il s'enthousiasme pour l'expérience des kibbutzim, et soutient les combats de la Haganah (comm. Jerôme Boquet). Vers 1950, il présente une demande de naturalisation française ; des rapports des Renseignements généraux le présentent comme suspect de « sympathies communistes »... Finalement, après maintes hésitations, la naturalisation est tout de même concédée.

7 Au cours des années 1960, Glasberg se rapproche d'Henri Curiel, dont l'organisation semi-clandestine, "Solidarité ", aide les mouvements révolutionnaires du Tiers-Monde. Mais il va rompre avec Curiel à cause de son soutien à l'invasion soviétique de la Tchécoslovaquie en 1968. Après 1967, il va aussi prendre ses distances envers Israël, devenant un critique acerbe de la politique israélienne officielle, et un sympathisant actif de la cause palestinienne.

Marginal dans l'Église, Glasberg participe néanmoins, avec son ami dominicain progressiste Maurice Montuclard, à un mouvement comme Jeunesse de l'Église, fréquenté par des animateurs de la revue Esprit et de Témoignage Chrétien. Reste le mystère de son rapport intime à la foi chrétienne et au ministère sacerdotal. Selon ses plus proches amis (comm. Luc Dubrulle) l'abbé Glasberg était prêtre, mais n'était pas un homme d'Église. Il se méfiait de l'institution et ne s'y référait jamais. Sa foi n'avait rien de canonique, elle était intime et privée. Est-ce par souci de laïcité ? Est-ce par le désir de séparer, selon la doctrine de Jacques Maritain, le spirituel et le temporel ? L'énigme reste entière... Pour conclure avec Étienne Fouilloux, quoi qu'il en soit, l'abbé Glasberg, Juste parmi les Nations, n'échappe pas à l'histoire religieuse de notre temps. 